\title{
DA INVARIÂNCIA DAS LEIS DA FÍSICA À RELATIVIDADE DOS CORPOS EM MOVIMENTO: ENTRE LEIBNIZ E EINSTEIN *
}

From the invariance of the laws of physics to the relativity of bodies in motion: Between Leibniz and Einstein

André Luiz Bentes / Vinícius Carvalho da Silva **

Resumo: Nesse artigo analisamos como a filosofia natural de Leibniz contesta o cânone do espaço absoluto, defendendo a relatividade dos corpos em movimento e a natureza ideal do espaço e do tempo. Argumentamos que o postulado relativístico leibniziano não somente antecipou, mas também preparou, em termos conceituais mais amplos, as bases filosóficas para a elaboração do princípio da relatividade, tal como formulado por Einstein.

Palavras-chave: Leibniz. Einstein. Relatividade. Espaço. Tempo.

Abstract: In this article we analyze how Leibniz's natural philosophy challenges the canon of absolute space, by defending the relativity of bodies in motion and the ideal nature of space and time. We argue that the Leibnizian relativistic postulate not only anticipated, but also elaborated, in broader conceptual terms, the philosophical basis for the principle of relativity formulated by Einstein.

Keywords: Leibniz. Einstein. Relativity. Space. Time.

\footnotetext{
* Artigo recebido em 18/06/2020 e aprovado para publicação em 05/09/2021.

** André Luís Bentes, doutor em Filosofia pela Pontifícia Universidade Católica do Rio de Janeiro (PUC-Rio), é Professor de Filosofia na Universidade Federal do Tocantins (UFT). Vinícius Carvalho da Silva, doutor em Filosofia da Ciência e Teoria do Conhecimento pela Universidade do Estado do Rio de Janeiro (UERJ), é Professor de Filosofia da Universidade Federal do Mato Grosso do Sul (UFMS), colaborando na disciplina de Filosofia da Ciência na pós-graduação (mestrado e doutorado) em Biofísica do Instituto de Biofísica Carlos Chagas Filho da Universidade Federal do Rio de Janeiro (IBCCF-UFRJ).
} 


\section{Introdução}

A natureza do espaço e a estrutura do mundo são objetos de investigação filosófica desde a antiguidade. Os primeiros físicos ( $\varphi v \sigma \iota k o ̀ s$, physikós) ${ }^{1}$, ou cosmólogos, como Tales, posteriormente denominados genericamente de filósofos ou "filósofos da natureza", como em Aristóte$\mathrm{les}^{2}$, se dedicavam ao estudo do mundo físico e de suas propriedades. O que é o espaço? A concepção historicamente hegemônica preconiza que o espaço é uma entidade absoluta, uma substância universal, independente de todas as demais entidades físicas.

No presente artigo analisaremos, sobretudo, a noção de relatividade em Gottfried Wilhelm Leibniz. Na primeira parte investigaremos como tempo e espaço são entidades absolutas na filosofia natural newtoniana. Isso nos conduzirá à compreensão, ainda que em linhas gerais, de que a doutrina absolutista de Newton é de fundamental importância para entendermos a concepção relativística leibniziana, que a ela se contrapõe.

Na segunda parte nos debruçaremos sobre a filosofia de Leibniz, no que diz respeito ao espaço, tempo e movimento. Para tanto, analisaremos brevemente o significado do conceito de relatividade na história da filosofia natural, pontuando a diferença entre distintas formulações do princípio de relatividade. Veremos, assim, como o postulado de Leibniz, de que não há movimento absoluto é, essencialmente, o princípio da relatividade tal como definido por Einstein em sua teoria da relatividade. Em seguida discutiremos como a natureza do espaço é um problema filosófico tradicional e como o absolutismo pode ser considerado uma tese predominante desde a antiguidade grega. Isso nos oferece o tom da inovação conceitual da relatividade de Leibniz.

Na seção seguinte, pontuaremos a defesa que Leibniz faz de suas concepções nas correspondências que mantém com Samuel Clarke, defensor do sistema newtoniano, com o fim de apresentar o seu movimento argumentativo.

Por último, consideraremos a importância dos princípios de razão suficiente e identidade dos indiscerníveis na construção da idealidade do espaço e do tempo, em Leibniz. Nosso objetivo é demonstrar como Leibniz foi um pensador original ao lançar as bases do princípio da relatividade, tal como concebido por Einstein.

\footnotetext{
${ }^{1}$ Physikós, do grego, aquele cujo estudo é "concernente à natureza", o investigador da natureza ou simplesmente filósofo da natureza.

${ }^{2}$ Ver na Metafísica, p.ex.; a discussão sobre o pensamento dos "filósofos da natureza".
} 


\section{Tempo e Espaço absolutos na Filosofia Natural de Newton}

O contexto da nossa pesquisa, sobre a concepção de Leibniz acerca do tempo e do espaço, nos conduz a introduzir a concepção newtoniana sobre o tema, uma vez que nos ateremos neste estudo às correspondências de Leibniz direcionadas a Clarke, datadas a partir de 1715, onde se encontram recorrentes alusões e refutações às concepções de Newton.

É na oitava definição dos seus Princípios matemáticos da filosofia natural, precisamente em seu escólio respectivo que, de modo claro, Newton nos oferece a sua concepção de tempo e espaço. Em relação ao tempo, ele se refere de duas maneiras distintas: em primeiro lugar, "o tempo absoluto, verdadeiro e matemático flui sempre igual por si mesmo e por sua natureza, sem relação com qualquer coisa externa, chamando-se com outro nome duração"; em segundo, "o tempo relativo, aparente e vulgar é certa medida sensível e externa de duração por meio do movimento (seja exata, seja desigual), a qual vulgarmente se usa em vez do tempo verdadeiro, como são a hora, o dia, o mês, o ano". ${ }^{3}$

É evidente a primazia atribuída por Newton, a partir dos trechos que trouxemos, ao tempo absoluto, o verdadeiro, em contraposição ao relativo. Este está relacionado a uma impressão sensível, que a partir da duração de um movimento concebe intervalos do tempo.

Em relação ao espaço, Newton mantém uma dualidade, pois "o espaço absoluto, por sua natureza, sem nenhuma relação com algo externo, permanece sempre semelhante e imóvel"; enquanto "o relativo é certa medida ou dimensão móvel desse espaço, a qual nossos sentidos definem por sua situação relativamente aos corpos" ${ }^{4}{ }^{4}$ Assim, é o espaço absoluto, em sua imobilidade, a condição para um espaço relativo, o qual não constitui nada além de uma parte daquele.

Percebemos, em Newton, as concepções de tempo e espaço assumirem um caráter fundamental ao desenrolar dos acontecimentos externos, uma vez que ele os concebe como "formas particulares e não propriedades de formas particulares ou relacionadas entre $\mathrm{si}^{\prime \prime}$. A natureza absoluta de todo o espaço, em contraposição às partes relativas do espaço, é um pressuposto ontológico da mecânica newtoniana, como vemos em Física Moderna: origens clássicas e fundamentos quânticos, de Caruso e Oguri:

O espaço absoluto para Newton é uma necessidade lógica e ontológica. Mas não se pode perder de vista também suas concepções religiosas, que o

\footnotetext{
${ }^{3}$ NEWTON, 1974, p. 14.

${ }^{4}$ Idem.

${ }^{5}$ KORNER, S. Kant.Trad. Ignacio Zapata Tellechea. Madrid: Alianza, 1981, p. 31.
} 
levaram a conceber o espaço como o sensorium de Deus. Seu caráter absoluto é, por exemplo, indispensável em seu sistema para a compreensão da primeira lei de Newton. ${ }^{6}$

Diferentemente de Newton, para Leibniz, o espaço, assim como o tempo,

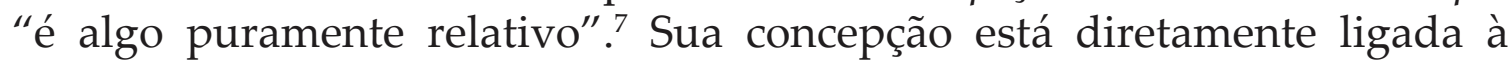
impossibilidade, atribuída por ele, de diferenciar objetos a partir de suas qualidades externas, sim, materiais, pois todas as denominações acerca de objetos devem estar fundadas em predicados internos. A partir daí esperamos compreender, em Leibniz, qual é a relação entre espaço e tempo e a indiscernibilidade de objetos.

\subsection{Da relatividade do movimento à idealidade do espaço e do tempo}

O conceito de relatividade possui diversos usos na história da física. Embora não sejam estranhos entre si, não podemos ignorar suas diferenças. Nesta oportunidade vamos destacar dois significados:

1. Princípio de relatividade nomológica ${ }^{8}$ (universalidade das leis da física)

2. Princípio da relatividade mecânica (relatividade dos corpos em movimento)

O princípio de relatividade nomológica, trata da universalidade e regularidade das leis da física:

A universalidade da física é descrita por um princípio básico, que talvez devesse ser chamado de axioma, por ser aceito sem demonstração devido a sua clareza e razoabilidade: o princípio da relatividade. Seu enunciado é o seguinte, As leis da física são as mesmas em qualquer referencial inercial. ${ }^{9}$

\footnotetext{
${ }^{6}$ CARUSO, F; OGURI, V. Física Moderna: Origens clássicas e fundamentos quânticos. Rio de Janeiro: Campus, 2006, p. 172.

${ }^{7}$ LEIBNIZ, G. W. Coleção Os pensadores. Tradução: Carlos Lopes de Mattos, Abril Cultural: São Paulo, 1974. p. 413.

${ }^{8}$ Embora na literatura os dois sentidos da relatividade sejam dados pelo contexto, ou em alguns casos se utilize "princípio de relatividade" para tratar da universalidade e invariância das leis da física e "princípio da relatividade" para tratar do problema dos corpos em movimento, aqui optamos por acrescentar, ao menos nesse momento inicial, o termo nomológico (de nomos, ordem, lei) ao primeiro sentido, e o termo mecânico ao segundo tipo. Nosso intuito é meramente didático, a fim de evitar que nossos leitores se confundam. Também se utiliza na literatura a mesma forma "princípio de relatividade", com "de", tanto para se referir à questão da universalidade e invariância das leis da física quanto para se referir ao problema dos corpos em movimento. Nesse caso o leitor não familiarizado deve ficar atento ao contexto. ${ }^{9}$ ROCHA, A.N.; RIZZUTI, B.F; MOTA, D.S. Transformações de Galileu e de Lorentz: um estudo via teoria de grupos. Rev. Bras. Ensino Fís. [online]. 2013, vol. 35, n.4, p.1. <acesso em: 31/05/2019>
} 
Tal definição é bem próxima a de Caruso e Oguri:

A ideia de que a Física deve ser a mesma para observadores que se deslocam uns em relação aos outros, em movimentos de translação uniforme, foi defendida por Galileu em seu Diálogo. (...) Esse princípio de absoluta equivalência entre dois referenciais que se movem relativamente em translação uniforme, isto é, entre referenciais inerciais, concebido em uma época de primazia da Mecânica, é a base do princípio de relatividade de Galileu, o qual implica o abandono de qualquer possibilidade de movimento absoluto. ${ }^{10}$

A citação acima mostra como os dois sentidos (nomológico e mecânico) da relatividade estariam conjugados. Do fato de que as leis da física sejam universais, sendo as mesmas em diferentes "sistemas referenciais", se segue que as mesmas leis se aplicam a todos os sistemas. Ora, se existem sistemas referenciais, e não um único sistema de referência em estado de repouso, logo nenhum referencial é absoluto. Se não há referencial absoluto, não há movimento absoluto. Os corpos se movimentam, em todos os sistemas, conforme as mesmas leis, mas em relação uns aos outros e não a um referencial absoluto.

Talvez o nome nos pareça inadequado e o mais razoável fosse "princípio da não relatividade", posto que o que ele aparentemente diz é que as leis da física são (ou devem ser) absolutas. Conforme Planck (2012), uma lei física possui um valor relativo quando seu escopo é limitado. Nesses casos, a lei aplica-se a determinados sistemas físicos, mas não a todos. Uma lei cujo valor fosse absoluto aplicar-se-ia a todos os sistemas físicos. Para Planck, a busca pelo absoluto é o grande objetivo (inalcançável) da ciência. Desejamos uma crescente unificação das leis da física, a conquista de leis cada vez mais simples e universais, revelando a ordem e unidade da natureza. Nesse sentido o princípio de relatividade, acima formulado, expressa a atitude filosófica geral da pesquisa científica.

A ciência busca uma imagem ordenada, simples e unificada do mundo, avançando do relativo ao absoluto - as leis físicas devem evoluir historicamente de um amplo, complexo e multifacetado conjunto de leis com valores relativos para um pequeno conjunto de leis universais simples, cujo valor (a abrangência da lei) se aproxima cada vez mais do absoluto (universalidade e unidade plenas).

O princípio de relatividade afirma que as leis da física são universais, que permanecem tal e qual em todos os sistemas referenciais. Não são as leis, mas sim os sistemas que mudam. Assim, a gravidade, por exemplo, tem validade universal (caberia falar em uma "universalidade fraca", posto que não se aplique a todos os domínios e sistemas físicos).

${ }^{10}$ CARUSO; OGURI, ob. cit. p. 177. 
A lei é a mesma em toda parte, já os efeitos gravitacionais são variados, porque os sistemas nos quais a gravidade se aplica são diferentes. Podemos dizer que os "efeitos" de uma lei são relativos às condições dos sistemas em que ela se aplica, mas o valor da lei é universal para todos os sistemas. Ora, os efeitos da gravitação universal na superfície do sol, na proximidade do horizonte de eventos de um buraco negro ou em uma estação espacial na órbita da terra são claramente díspares entre si, mas decorrem todos da mesma lei universal, como efeitos relativos deduzidos de uma causa única.

A lei da gravidade, ainda assim, possuiria valor relativo, logo, não absoluto, se quisermos trabalhar com os conceitos de Planck. Dizendo de outra forma, a lei de gravitação possuiria alto grau de universalidade, pois se aplicaria a uma vasta gama de sistemas físicos. Mas assim como se aproximar da verdade é diferente de ser absolutamente verdadeiro, se aproximar da universalidade não é o mesmo que ser, stricu sensu, universal. A lei de gravitação universal, na física clássica, se conforma ao princípio de relatividade: a lei permanece tal e qual em todos os sistemas físicos em que se aplica.

Todavia, no sentido do pensamento de Planck, a lei não possui valor absoluto, pois não se aplica a todos os sistemas físicos. Não temos, por exemplo, uma boa teoria da gravidade, ou ao menos uma teoria consensual, para as escalas quânticas. Assim, o valor da lei permanece relativo aos sistemas físicos macroscópicos, mas, ainda assim, não aos sistemas macroscópicos envolvendo velocidades próximas à da luz ou grandes efeitos gravitacionais, casos em que é a física relativística, e não a mecânica newtoniana, que deve ser considerada.

Einstein, por sua vez, definiu o princípio de relatividade, neste primeiro sentido, como "a suposição de que as leis físicas são independentes do estado de movimento do sistema referencial"11. Em Sobre a eletrodinâmica dos corpos em movimento, Einstein defendeu que as leis da física são as mesmas em todos os sistemas inerciais (1905). Em um manuscrito de revisão de 1912, um texto não publicado, o físico filósofo volta a definir o princípio de relatividade. Segundo John Stachel, ele enuncia o que seria o "princípio de relatividade da mecânica clássica"12. Para Einstein:

Todo referencial que está em movimento de translação uniforme com respeito a um referencial legítimo é, por sua vez, um referencial legítimo. Com relação a todos esses sistemas legítimos, as leis do movimento de qualquer sistema (mecânico) são as mesmas. ${ }^{13}$

\footnotetext{
${ }^{11}$ EINSTEIN, A. Sobre o princípio da relatividade e suas implicações. Rev. Bras. Ensino Fís. [online]., vol.27, n.1, 2005 p.56. <acesso em: 08/05/2019>.

${ }_{12}$ STACHEL, J. O manuscrito de Einstein de 1912 como pista para o desenvolvimento da teoria da relatividade restrita. Sci. stud. [online]. 2005, vol.3, n.4 [cited 2019-06-12], p. 586

${ }^{13}$ EINSTEIN apud STACHEL, 2005, p. 586.
} 
Nessas três ocasiões Einstein formula o princípio de relatividade com palavras diferentes, mas preservando o mesmo significado: as leis da física são as mesmas, independente do "sistema legítimo" ou sistema inercial que tomamos.

Seria enganoso sugerir que o princípio de relatividade, que trata da universalidade das leis da física, e o princípio da relatividade, que trata do movimento relativo dos corpos, são dois princípios não somente diferentes, como independentes. Ora, se em todos os sistemas inerciais o movimento dos corpos é relativo, então podemos considerar a relatividade do movimento como uma lei física universal, isto é, "independente do estado de movimento do sistema referencial".

Sendo assim, o princípio da relatividade (do movimento) é um caso do "princípio de relatividade" (de universalidade e invariância das leis físicas). Se em todos os sistemas inerciais o movimento é relativo, logo não há "movimento absoluto", e se não há movimento absoluto, ou se o movimento não pode ser detectado tomando o espaço como referencial absoluto, logo a existência do "espaço absoluto" é logicamente dispensável e fisicamente irrelevante para a formulação de um sistema mecânico universalmente válido. ${ }^{14}$

Neste artigo não tratamos diretamente do "princípio de relatividade" no sentido da universalidade das leis da física. É o segundo sentido de relatividade que vem ao caso - o sentido do "princípio da relatividade", da teoria da relatividade de Einstein. É da relatividade dos corpos em movimento que tratamos, pois esse é o caminho que nos remeterá à questão da natureza do espaço em Leibniz. Neste segundo sentido, Einstein define o princípio da relatividade da seguinte forma:

O nome "teoria da relatividade" está ligado ao fato de que o movimento, do ponto de vista da experiência possível, aparece sempre como o movimento relativo de um objeto em relação a outro (por exemplo, de um automóvel com referência ao solo, ou da Terra em relação ao Sol e às estrelas fixas). O movimento jamais é observável como "movimento em relação ao espaço", ou, como já se expressou, como "movimento absoluto". O "princípio da relatividade", em seu sentido mais amplo, está contido na afirmação: a totalidade dos fenômenos físicos é de caráter tal que não fornece base para a introdução do conceito de "movimento absoluto", ou, de forma mais breve, mas menos precisa: não há movimento absoluto. ${ }^{15}$

\footnotetext{
${ }^{14}$ Roberto de Andrade Martins mostra como a relação desses dois sentidos do princípio de relatividade (universalidade das leis da física e relatividade do movimento) é imbricada: "A teoria da relatividade especial mostra como se transformam as grandezas físicas entre dois referenciais inerciais em movimento relativo, assumindo que as leis básicas da física são as mesmas em todos esses referenciais" (Martins. 2005, p. 28). Essa passagem reforça o que dissemos acima. O princípio da teoria da relatividade (do movimento) é um caso do princípio de relatividade (da universalidade das leis da física). Formulando de outro modo: o princípio de relatividade (universalidade) é um pressuposto do princípio da relatividade (movimento) na teoria da relatividade de Einstein.

${ }^{15}$ EINSTEIN, ob. cit., 2005, p. 47.
} 
Quando falamos em "relatividade" aqui, focamos na questão da natureza ideal do espaço e do tempo em Leibniz, em contraposição ao espaço e tempo absolutos de Newton.

Ainda no escopo da física clássica, falaremos no "movimento relativo" dos corpos no espaço absoluto newtoniano. A definição do "princípio da relatividade" que Einstein fornece acima é totalmente compatível com a filosofia natural de Leibniz: "não há movimento absoluto". Dizendo de outra forma, propomos que o princípio da relatividade tal como definido por Einstein no texto selecionado foi formulado séculos antes por Leibniz: todo movimento é relativo, posto que não haja espaço absoluto para servir como referencial universal.

\subsection{A natureza do espaço e a relatividade}

A discussão acerca da natureza do espaço remonta aos cosmólogos e físicos gregos, geralmente chamados de filósofos da natureza e situados entre os pré-socráticos. Poderíamos apontar a cosmovisão parmenidiana como uma das primeiras concepções absolutistas do espaço. Em O Mundo de Parmênides, Karl Popper conjectura que a doutrina newtoniana do espaço absoluto possui, de algum modo, um parentesco com a cosmovisão do eleata: "Creio que Newton adotou a teoria da divindade e onipresença do espaço - ideia talvez não tão distante da Via da Verdade". ${ }^{16}$

Um espaço absoluto também é pressuposto pelo atomismo grego de Leucipo e Demócrito, para os quais a plural e complexa variedade dos eventos físicos pode ser explicada por meio de causas únicas e simples: átomos em movimento no espaço vazio.

Para José Lourenço Cindra, a noção, ainda que vaga, de um "princípio de relatividade do movimento" também remontaria à antiguidade grega. A relatividade estaria implícita no heliocentrismo de Aristarco. ${ }^{17}$ Em Esboço da evolução histórica do princípio de relatividade, Cindra destaca como foi Galileu quem formulou o princípio de relatividade com clareza ao sustentar que "não podemos detectar o movimento retilíneo uniforme (movimento inercial) a menos que tomemos outro corpo como referencial". ${ }^{18}$

Podemos dizer que o princípio de relatividade do movimento em Galileu não possui uma 'profundidade ontológica', isto é, não trata da natureza

\footnotetext{
${ }^{16}$ POPPER, K. O mundo de Parmênides: Ensaios sobre o iluminismo pré-socrático. Roberto Leal Ferreira (Trad.). São Paulo: Editora Unesp, 2014, p. 154.

${ }^{17}$ CINDRA, J.L. Esboço da evolução histórica do princípio de relatividade. Rev. Bras. Ensino Fís. [online]. Vol. 16 nr. 1 a 4 1994, p. 26.

${ }^{18}$ Ibidem, p. 27.
} 
do espaço e da estrutura do mundo. Estabelece somente que não é possível conhecer o estado de movimento inercial de um corpo A sem tomar, como referencial, sua posição relativa a outro corpo B qualquer. Com isso, temos um enunciado acerca do movimento dos corpos no espaço e dos nossos métodos de detecção do movimento, mas não uma resposta para a questão "o que é o espaço?", como aparecerá tanto em Newton quanto em Leibniz.

O princípio de relatividade do movimento não é um postulado acerca da estrutura do mundo. É um princípio basilar da física clássica, totalmente compatível com uma ontologia absolutista do espaço. Imaginemos a seguinte experiência de pensamento: tomemos o espaço como uma substância homogênea e isotrópica, que se estende igual e infinitamente em todas as direções. Imaginemos que todas as posições possíveis podem ser descritas como "lugares" dessa substância, sem que a substância em si, em sua totalidade, ocupe um "lugar". Para tanto, devemos conceber que tal substância é universal e mais do que onipresente - é a própria condição de possibilidade de toda e qualquer presença em sentido material. Se $x$ é o caso, e $x$ é uma entidade física qualquer, então $x$ existe nessa substância, que é o palco absoluto de tudo aquilo que é. Agora imaginemos essa substância como um continuum sem propriedades sensíveis. Um campo translúcido e indetectável pela visão. Em seguida, vamos introduzir nesse mundo logicamente possível um único corpo material $\mathrm{A}$, um ponto colorido qualquer. Estará em movimento? Possuirá estado inercial?

Pelo princípio de Galileu, não podemos responder tais questões, a não ser que em nosso universo exista ao menos um segundo corpo $B$, que não mantenha distância constante de A. Caso os dois corpos estejam parados, ou ocupem posições paralelas em movimento retilíneo uniforme, à mesma velocidade, será necessário um terceiro corpo $\mathrm{C}$, e assim por diante. Galileu compreendeu que podemos detectar o estado inercial de um corpo no espaço somente a partir da relação entre o corpo em questão e outros corpos referenciais. Por isso, o estado de um corpo A é relativo ao estado de um corpo B. Da relatividade do movimento dos corpos não se passa à relatividade do próprio espaço.

Em nosso experimento mental, para chegarmos ao princípio de relatividade do movimento, de Galileu, em nenhum momento tivemos que postular que o espaço não é absoluto. Pelo contrário, é justamente a natureza absoluta do espaço, o fato de ser uma substância universal, autônoma, completamente independente, que nos força a recorrer a outros corpos referenciais para verificar o movimento de um corpo.

Com Galileu, podemos rechaçar a possibilidade de movimento absoluto, assumindo a relatividade dos corpos em movimento, sem, contudo, tratar da natureza do espaço. Já a relatividade de Leibniz não é a relatividade dos corpos em movimento no espaço absoluto, mas da própria realidade 
objetiva do espaço. $\mathrm{O}$ que se nega não é a possibilidade de detectarmos o estado inercial de um corpo A que se move ad aeternum em um espaço absoluto, sem a devida referência relativa a um corpo B, mas o espaço absoluto per si. Mais do que isso: Leibniz não concebe que há movimentos relativos no espaço, mas que o próprio espaço não é outra coisa senão um conjunto ideal ordenado de entidades articuladas relativamente umas às outras. Leibniz pressupõe a idealidade do espaço, não admitindo, como Descartes e Newton, que possamos tratar do espaço como uma entidade física objetiva fora da mente. ${ }^{19}$

A crítica de Leibniz ao espaço absoluto newtoniano promoveria uma resignificação do princípio de relatividade do movimento na filosofia natural. A relatividade defendida por Leibniz não decorreria do princípio de Galileu. Enquanto Galileu, Descartes, Newton e outros, assumiram alguma forma de realismo, pressupondo o espaço como entidade física independente do sujeito cognoscente, Leibniz sustentou a idealidade do espaço. O espaço em Leibniz é tomado como um ente ideal, um conceito, uma ferramenta intelectual, um instrumento teórico, utilizado para nos auxiliar quando tratamos das relações mecânicas entre os corpos:

Para Leibniz, falar ontologicamente do espaço (como receptáculo absoluto) é algo que não tem fundamento. O espaço para Leibniz é antes um conceito relacional, ou seja, é um conceito que podemos usar dada a ordenação dos corpos. $^{20}$

Conforme Joseph Agassi em Leibniz's place in the history of physics, a relatividade leibniziana romperia com uma longa tradição de teorias de espaço absoluto, criando as bases filosóficas para uma física relativística. Para Agassi, Leibniz concebia o espaço "não como uma substância autônoma - como pensavam Demócrito, Platão, Euclides, Descartes e Newton - mas como um sistema ordenado de relações entre coisas". ${ }^{21}$ Tal teoria do espaço seria aceita por Einstein, e dele receberia o devido tratamento matemático:

Einstein declarou-se leibniziano e sustentou que a superioridade da filosofia de Leibniz era tão óbvia que alguém poderia explicar o triunfo newtoniano somente pela falta dos instrumentos matemáticos necessários à Leibniz para desenvolver uma teoria física capaz de competir com a teoria de Newton. ${ }^{22}$

\footnotetext{
${ }^{19}$ Ver HUGGETT, N; HOEFER, C. Absolute and Relational Theories of Space and Motion. In: The Stanford Encyclopedia of Philosophy (Spring 2018 Edition), Edward N. Zalta (ed.).

${ }^{20}$ CARDENAS CASTANEDA, L; FLÓREZ, C. D. B. Leibniz, Mach y Einstein: Tres objeciones al espacio absoluto de Newton. discus.filos [online]. 2009, vol.10, n.15. <acesso em: 10/06/2019>, 2009, p .57 .

${ }^{21}$ AGASSI, J. Leibniz's place in the history of physics. Journal of the History of Ideas. Vol. 30, No.

3 (Jul. - Sep., 1969), p. 331.

${ }^{22}$ Idem.
} 
A despeito da afirmação de Agassi na citação acima, precisamos destacar que as relações entre Leibniz e Einstein são subestimadas na literatura. Poucos autores destacam a importância de Leibniz como pioneiro de uma perspectiva relativística em física e o próprio Einstein pouco abordou tal questão. A história da relatividade geralmente omite a contribuição de Leibniz. No entanto, não podemos adotar um anacronismo descuidado e afirmar que foi Leibniz quem formulou, antes de Einstein, o princípio da relatividade. O que afirmamos é simples: o postulado geral, de que não há movimento absoluto, ou melhor, que nenhum movimento tem como referencial o espaço absoluto, já se encontra na filosofia natural de Leibniz, antes de tornar-se um postulado físico devidamente formulado em bases matemáticas na física relativística de Einstein:

... a ideia de invariância, centro da teoria da Relatividade, já pairava no espírito de Leibniz e de Galileu. Mas, foi o gênio de Einstein que explicitou tal princípio e o elevou a categoria de postulado (com o nome de principio da relatividade). ${ }^{23}$

Este é o ponto que objetivamos ressaltar: se não podemos falar em um continuísmo entre Leibniz e Einstein, tampouco nos cabe ignorar que o princípio da relatividade, peça fundamental da teoria da relatividade de Einstein parece poder ser, conceitualmente, a formulação físico-matemática do postulado leibniziano da relatividade do movimento em sua teoria da idealidade do espaço.

\section{O debate entre Leibniz e Clarke}

$\mathrm{Na}$ terceira de suas cartas endereçadas a Clarke, Leibniz evidencia a necessidade de manter sua posição acerca da relatividade espacial para que seu axioma, sobre uma proposição verdadeira exigir que o predicado esteja contido no sujeito, seja mantido:

... se o espaço fosse um ser absoluto, sucederia alguma coisa de que seria impossível uma razão suficiente, o que é ainda nosso axioma. Eis como o provo. O espaço é algo absolutamente uniforme; e, sem as coisas postas nele, um ponto do espaço não difere absolutamente nada de um outro ponto. Ora, disso se segue (suposto que o espaço seja alguma coisa em si mesmo fora da ordem dos corpos entre si) ser impossível que haja uma razão por que Deus, conservando as mesmas situações dos corpos entre si, os tenha colocado assim e não de outro modo. ${ }^{24}$

${ }^{23}$ MENESES, R.D.B. Relatividade restrita de Einstein: Fundamentos filosóficos. Perspectiva Filosófica. Volume II, Número 24. Julho/Dezembro de 2005, p. 48.

${ }^{24}$ LEIBNIZ, ob. cit. p. 413. 
A relatividade do espaço é um pressuposto necessário à validade do princípio de razão suficiente ${ }^{25}$, na concepção de Leibniz. Já na segunda carta a Clarke, ele demonstra preocupação com aqueles que acreditaram, ao pensar em um espaço absoluto, "ser ele o próprio Deus" ${ }^{26}$, e descarta tal possibilidade pelo fato do espaço possuir partes.

É pela noção de ordem que Leibniz concebe o tempo e o espaço: este "na ordem das coexistências", aquele "na ordem das sucessões". ${ }^{27} \mathrm{O}$ espaço oferece a possibilidade de nos referirmos às coisas que existem ao mesmo tempo, enquanto o tempo nos permite referirmo-nos à ordem da sucessão dos acontecimentos que coexistem. Ambos nos servem enquanto um sistema de referências para lidar com as coisas "sem entrar em seu modo de existir".$^{28}$ Não será, portanto, através de um predicado espaço-temporal, ou seja, de um predicado externo, que poderemos distinguir os objetos.

Somos levados a refletir acerca da noção de intervalo a partir da concepção de tempo enquanto "ordem das sucessões". Intervalo aqui parece assumir o caráter de "uma ordem serial de antes e depois". ${ }^{29}$ Em relação a dois intervalos concebemos uma duração, contudo "o tempo não é a duração". ${ }^{30}$ Leibniz atribui às coisas extensas a duração como uma propriedade; o mesmo não pode ser atribuído ao tempo, por este ser ideal, contínuo e não existir atualmente ${ }^{31}$ :

Com efeito, como poderia existir uma coisa de que jamais nenhuma parte existe? Ora, do tempo não existem jamais senão instantes, e estes não são nem sequer uma parte do tempo. Quem considerar essas observações, compreenderá bem que o tempo não poderia ser senão uma coisa ideal, e a analogia do tempo e do espaço logo fará ver que um é tão ideal quanto o outro. ${ }^{32}$

A duração, portanto, diz respeito às coisas extensas na medida em que se referem a, pelo menos, dois intervalos, que por sua vez estão relacionados à "ordem das sucessões", isto é, ao tempo.

\footnotetext{
${ }^{25}$ Por meio deste princípio, Leibniz acredita afirmar "em Deus o poder de escolher, pois que se funda esse poder na razão da escolha conforme sua sabedoria" (Leibniz, ob cit. p. 414). Entendemos aqui tal princípio como referente à razão pela qual "Deus ordena o universo do modo que ele faz e não de algum outro modo" (CHERNOFF, F. Leibniz's principle of identity of indiscernibles. In: Gottfried Wilhelm Leibniz: critical assessments. Routledge: Nova Yorque, 1994, p. 114).

${ }^{26}$ Ibidem, p. 412.

${ }^{27}$ Ibidem, p. 413.

${ }^{28}$ Idem.

${ }^{29}$ WINTERBOURNE, A.T. On the Metaphysics of Leibnizian Space and time. In: Gottfried Wilhelm Leibniz: critical assessments. Nova York: Routledge, 1994, p. 62.

${ }^{30}$ LEIBNIZ, ob. cit. 1974, p. 437.

${ }^{31}$ Ver, a esse respeito, COVER, J. A.; HARTZ, G. A. Space and Time in the Leibnizian Metaphysic. In: Gottfried Wilhelm Leibniz: critical assessments. Routledge: Nova Yorque, 1994, p.88: COVER; HARTZ, 1994, p. 88: “... as partes de coisas ideais comoespaço e tempo são meramente possíveis e assim não existem atualmente em qualquer lugar da natureza. Apesar desta ausência das partes, somos capazes de ter o conceito de um inteiro".

${ }^{32}$ LEIBNIZ, ob. cit. p. 439.
} 
Em relação ao espaço, será a noção de lugar também fundamental. Leibniz a concebe, em sua quinta carta à Clarke, do seguinte modo:

... lugar é aquilo que se diz o mesmo em relação a $\mathrm{A}$ e a $\mathrm{B}$, quando a relação de coexistência de $B$ com $C, E, F, G$, etc., convém inteiramente com a relação de coexistência que A tivera com os mesmos, supondo-se que não tenha havido nenhuma causa de mudança em C, E, F, G, etc." (...) lugar é aquilo que é o mesmo em momentos diferentes de dois existentes, embora diferentes, quando suas relações de coexistência com certos existentes, que desde um desses momentos até outro são supostos fixos, convêm inteiramente. ${ }^{33}$

É importante ressaltar que o espaço se constitui aqui basicamente enquanto relação de lugares. Leibniz chega a afirmar que "o que abrange todos esses lugares é que se chama espaço". ${ }^{34}$ Esses lugares são ocupados por coexistentes e só poderão ser concebidos como um mesmo lugar, a partir da referência de um existente fixo. Em outros termos, isso significa que somente de modo relativo é possível que nos refiramos ao espaço:

Isso demonstra que para ter a idéia do lugar, e por conseqüência do espaço, basta considerar essas relações e as regras de suas transformações, sem necessidade de imaginar aqui nenhuma realidade absoluta fora das coisas cuja situação se considera. ${ }^{35}$

O lugar, portanto, nada mais é do que um ponto de referência para nos relacionarmos com as coisas que coexistem ${ }^{36}$. Ao que chamamos referência, porém, para o ponto no espaço onde se encontrara outrora um corpo e onde agora se encontra outro, que é o próprio lugar, difere da relação que estes corpos possuem com seus coexistentes, ainda que ocupem, em intervalos diferentes, o mesmo lugar. Isso ocorre porque "dois sujeitos diferentes [...] não poderiam ter precisamente a mesma situação individual, não podendo o mesmo acidente individual encontrar-se em dois sujeitos, nem passar de sujeito para sujeito" ${ }^{37}$

A partir deste ponto, irá Leibniz, já em sua quinta carta a Clarke, demonstrar por que considera um erro (ao referir-se à realidade) atribuir as mesmas relações espaciais a dois sujeitos diferentes, a saber, pela impossibilidade de que haja nos "acidentes que estão nos sujeitos, alguma coisa que lhes corresponda fora dos sujeitos" ${ }^{38}$ A noção de acidente envolve a impossibilidade deste, enquanto o mesmo, ser relacionado a mais de um sujeito.

\footnotetext{
${ }^{33}$ Ibidem, p. 437-8.

${ }^{34}$ Idem.

${ }^{35}$ Idem.

${ }^{36}$ Ver ISHIGURO, H. Leibniz's philosophy of logic and language. Cambridge: Londres e New York, 1990, p. 143: “... segundo Leibniz, nós só individuamos lugares como pontos de referência para coisas nas quais ocupam certa ordem de coexistência".

${ }^{37}$ Ibidem, p. 438.

${ }^{38}$ Idem.
} 
Assim, somente idealmente se poderia conceber tal relação, promovida pela "imaginação dos homens", ao conceber uma relação entre dois sujeitos na ausência de uma referência a um existente fixo, na medida em que "é essa analogia que faz com que se imaginem lugares, vestígios e espaços, ainda que coisas não passem na verdade de relações e, de forma alguma, não sejam uma realidade absoluta" ${ }^{39}$

Assim, a realidade se constitui como um complexo de relações entre corpos. Sua principal característica é a de possuir partes indefinidas, pois os corpos não passam de agregados que resultam das mônadas, estas substâncias simples que os fundamentam. Deste modo, os corpos possuem partes distintas que são anteriores ao todo, característica de tudo aquilo que é real (excetuando-se as mônadas, que são reais e não têm partes). $\mathrm{O}$ que é ideal, ao contrário (e pensamos aqui no espaço e no tempo), consiste naquilo que é dado, enquanto um objeto do pensamento, primeiramente como um inteiro, um todo contínuo, para que suas partes (e pensamos aqui nas relações) possam ser concebidas consequentemente.

\subsection{O princípio de identidade dos indiscerníveis}

Cabe-nos agora refletir acerca de uma questão: existe alguma relação entre espaço e tempo e a diferença concernente a dois sujeitos? Para isso, precisaremos compreender, em primeiro lugar, o princípio de identidade dos indiscerníveis.

$\mathrm{Na}$ terceira correspondência direcionada a Clarke, mais especificamente no argumento em que refuta a possibilidade de julgar o espaço como "uma substância, ou ao menos algum ser absoluto" 40 , Leibniz rejeita tal possibilidade por esta negar o princípio de razão suficiente, conforme vimos, pois se o "espaço é homogêneo", então "dois pontos quaisquer do espaço vazio são iguais" ${ }^{41}$ e Deus não teria uma razão para organizar o mundo desta e não de outra maneira:

... segue (suposto que o espaço seja alguma coisa em si mesmo fora da ordem dos corpos entre si) ser impossível que haja uma razão por que Deus, conservando as mesmas situações dos corpos entre si, os tenha colocado assim e não de outro modo, e por que tudo não se fez ao contrário (por exemplo), trocando-se o Oriente e o Ocidente. ${ }^{42}$

Atentando ao exemplo meridional de Leibniz e pressupondo que o espaço não seja relativo, mas sim absoluto, a ordem do universo seria distinta

\footnotetext{
${ }^{39}$ Ibidem, p. 439.

${ }^{40}$ LEIBNIZ, ob. cit., p. 413.

${ }^{41}$ CHERNOFF, ob. cit., p. 114.

${ }^{42}$ LEIBNIZ, ob. cit., p. 413.
} 
de uma ordem contrária ${ }^{43}$ e teríamos uma concepção de mundo que restringiria a razão pela qual Deus fez o mundo tal como o conhecemos. Qual lei ou princípio privilegiaria um lugar do espaço dentre todos os restantes? Por que Deus teria disposto ou arranjado os corpos no espaço desta e não de outra maneira? Ao contrário, se concebermos um espaço relativo, um mundo possível onde os lados meridionais estão invertidos difere somente em ordem do mundo atual:

... se o espaço não é mais que essa ordem ou relação, e não é, sem os corpos, senão a possibilidade de aí os pôr, esses dois estados, um tal como é, e o outro suposto ao contrário, não diferiram entre si. A diferença deles não se encontra, pois, senão em nossa suposição quimérica da realidade do espaço em si mesmo. Mas, na verdade, um seria justamente a mesma coisa que o outro, como são absolutamente indiscerníveis; e, por conseguinte, não se poderá perguntar a razão de se preferir um ao outro. ${ }^{44}$

Pressupondo um espaço relativo, um estado do universo contrário ao que conhecemos é indiscernível deste, uma vez que não há um "espaço em si mesmo" para utilizarmos como referência. "Se dois estados são indiscerníveis, então um é idêntico ao outro" e Deus não precisa excluir um estado para criar o outro. O espaço se constitui, desse modo, por meio de uma série de relações ideais, enquanto "o mundo material é o mesmo" em seu estado atual ou em um estado contrário, "exceto para relações espaciais entre pontos materiais". ${ }^{45}$

O princípio de identidade dos indiscerníveis, segundo Fred Chernoff, é utilizado até aqui como um "princípio lógico", pois, para ele, Leibniz faz uso deste para "argüir que duas entidades ideais (pontos de relações espaciais) são idênticas" e negar "a possibilidade de concebê-las como distintas". ${ }^{46}$ De modo geral, como Hidé Ishiguro concebe o princípio de identidade dos indiscerníveis, "se tudo que é verdade de $\mathrm{A}$ é verdade de $\mathrm{B}$, e vice versa, e ainda se não há diferença discernível entre A e B, então A é idêntico a B". ${ }^{47}$

Se acrescentarmos elementos (ou objetos) ao "campo", p.ex., um objeto $\mathrm{C}$, poderíamos prosseguir indefinidamente, o que nos levaria, por exemplo, a um dos axiomas de Euclides. Ora, se dois objetos são iguais a um terceiro, são iguais entre si ( $\mathrm{Se} A=B$ e $C=B$, então $A=C$ ). Note-se que, no caso de Leibniz, não estamos a falar de identidade quanto à espécie ou de identidade qualitativa em sentido mais ou menos vago. Trata-se de uma lei lógica de identidade numérica que pressupõe que entre dois ou mais

\footnotetext{
${ }^{43}$ Ver a reconstrução do argumento de Leibniz, sobre a negação do princípio de identidade dos indiscerníveis a partir de uma concepção absoluta do espaço, realizada por Fred Chernoff, ob. cit. p. 114.

${ }^{44}$ LEIBNIZ, ob. cit., p. 413.

${ }^{45}$ Idem.

${ }^{46}$ CHERNOFF, ob. cit. p. 114.

${ }^{47}$ ISHIGURO, ob. cit. p. 17.
} 
objetos idênticos todas as suas partes sejam comutáveis sem prejuízo ou variação formal e ontológica. É a chamada Lei de Leibniz (LL):

$$
\begin{gathered}
(\mathrm{LL}) \mathrm{x}=\mathrm{y} \equiv_{\operatorname{def}} \mathrm{FF}(\mathrm{F}(x) \leftrightarrow \mathrm{F}(y)){ }^{[48]} \\
\mathrm{Ou} \\
(\mathrm{V} x)(\mathrm{Vy} y)\left(x=y \leftrightarrow(\mathrm{VF})[\mathrm{F}(x) \leftrightarrow \mathrm{F}(y)]^{[49]}\right.
\end{gathered}
$$

Em um mundo logicamente possível qualquer, imaginemos dois sistemas compostos por $n$ partes. Ora, os dois sistemas são indiscerníveis se, e somente se, todas as suas partes forem comutáveis, e se após cada troca os dois sistemas permanecerem tais e quais, não sofrendo, aquele "mundo", a mínima modificação no arranjo de suas mínimas partes constituintes e nas relações das partes entre si.

Na formulação de Tugenhadt e Wolf, em Propedêutica lógico-semântica, podemos escrever a lei de Leibniz do seguinte modo:

(F) $(\mathrm{Fa} \equiv \mathrm{Fb})$

Tal fórmula diz que "dois objetos devem ser numericamente idênticos se, e somente se, eles não podem ser diferenciados por meio de nenhuma propriedade"..$^{50}$

Concebamos dois mundos $\alpha$ e $\beta$ logicamente possíveis, constituídos por puros espaço e tempo absolutos, sem quaisquer corpos ou eventos. Como falar em "lugares" e "instantes", a não ser que, em tais mundos admitamos que todos os lugares e instantes são comutáveis, isto é, podem ser trocados sem que o todo deixe de ser idêntico a si mesmo, preservando, parte por parte, sua forma e ontologia. Qualquer troca e os dois mundos permaneceriam tais e quais. E se trocássemos não somente as partes, mais os polos de um pelas partes e os polos de outro, ainda assim um observador não poderia dizer qual é qual, e nem apontar qualquer diferença antes ou depois da troca.

Os mundos $\alpha$ e $\beta$ seriam, pois, indiscerníveis. Mas se $\alpha$ ou $\beta$ ou ambos, possuíssem distintos corpos em movimento, em direções diversas e em velocidades diferentes, nem os corpos de $\alpha$ poderiam ser livremente trocados pelos corpos de $\beta$, nem um universo poderia ser tomado pelo outro. A identidade de cada qual seria dada por sua configuração especial, isto é, pelo arranjo único resultante do movimento relativo dos seus corpos entre si.

\footnotetext{
${ }^{48}$ Formalização da Lei de Leibniz disponível em CASU, M; ALBERGANTE, L. Identity in the Real World. In. VALVERDÚ, J. Thinking Machines and the Philosophy of Computer Science. New York: IGI, 2010, p. 109.

${ }^{49}$ COCCHIARELLA, N. B. Formal Ontology and Conceptual Realism. Dordrecht: Springer, 2007, p. 126.

${ }^{50}$ TUGENHADT, E., WOLF, U. Propedêutica Lógico-semântica. Trad. de Fernando Augusto da Rocha Rodrigues. - Petrópolis, RJ : Vozes, 1997, p. 133.
} 
Em um mundo onde o espaço é relativo e não há um "existente fixo", como referência, a inversão dos seus lados meridionais em nada difere, isto é, de modo ideal são idênticos. No entanto, no que se refere ao mundo atual (ou mesmo possível) Leibniz afirma que "não há dois indivíduos indiscerníveis" e, com isso, não serão apenas as relações de tempo e espaço suficientes para distinguir duas substâncias individuais, ainda que se constituam como suas propriedades. Isso enfatiza que apenas de modo ideal poderíamos conceber seu exemplo sobre a inversão do estado do universo:

Pôr duas coisas indiscerníveis é admitir a mesma coisa sob dois nomes. Assim a hipótese de que o universo poderia ter tido primeiro uma outra posição temporal e local do que aconteceu efetivamente, e que entretanto todas as suas partes teriam a mesma posição relativa que a recebida com efeito, é uma ficção impossível. ${ }^{51}$

Como já vimos, para Leibniz, apenas idealmente dois sujeitos podem compartilhar um mesmo acidente, isto é, no mundo atual, material, isto não é possível. Isso nos conduz a refletir acerca das limitações materiais concernentes às suas relações possíveis. No que diz respeito ao espaço cabe, assim, a questão: "poderia o mundo material ter ocupado alguma outra região do espaço diferente da que ocupa de fato"? ?52 Estamos agora na discussão sobre a diferença entre mundos possíveis. Pensemos que estes mundos possuam estados possíveis. Quando ocorre de um estado possível não extinguir a possibilidade de um estado distinto, temos então estados compossíveis. Ao contrário, "se dois estados são distintos, então eles são membros de diferentes mundos possíveis". ${ }^{53}$ Assim, somos levados a crer que apenas em outro mundo possível algo material ocuparia um lugar diferente.

Os estados diversos dos que compõem o mundo atual são, portanto, somente possíveis. Conceber que os mesmos estados (do mundo atual) poderiam ocupar um lugar distinto do que ocupam de fato é pressupor que há um espaço absoluto, em si, fora das relações entre os estados. Pressupondo um espaço relativo a estados, sugerir que estes poderiam ocupar posições diferentes, para Leibniz, corresponde a uma ficção impossível:

Dizer que Deus faz adiantar-se o universo em linha reta ou outra qualquer sem nada mudar nele é ainda uma suposição quimérica. De fato, dois estados indiscerníveis são o mesmo estado, e por conseguinte, é uma mudança que não muda nada. Além disso, é uma coisa sem pé nem cabeça (sem nenhuma razão). Ora, Deus não faz nada sem razão, e é impossível que aqui haja alguma. De resto, seria agendo nihil agere (agindo, não fazer nada), como acabo de dizer, por causa da indiscernibilidade. ${ }^{54}$

${ }^{51}$ LEIBNIZ, ob. cit. p. 419.

${ }^{52}$ CHERNOFF, ob. cit., p. 119.

${ }^{53}$ Idem.

${ }^{54}$ LEIBNIZ, ob. cit., p. 419. 
É justamente pela relatividade do espaço, isto é, por este se constituir enquanto relação ideal entre os corpos, que não faz sentido, para Leibniz, pensar a possibilidade de ocuparem um lugar distinto no mundo atual. Isso diria respeito, talvez, a outros mundos possíveis. De qualquer modo, por constituírem uma relação entre si, os estados, tais como são, seriam indiscerníveis se fossem adiantados em linha reta (pensando em um espaço absoluto) e Deus não teria razão para movê-los, pois "nas coisas absolutamente indiferentes, não há escolha e por conseguinte nem eleição nem vontade, pois que a escolha deve ter alguma razão ou princípio".$^{55}$ Do mesmo modo Leibniz se refere ao tempo:

É uma ficção semelhante, i. e, impossível supor que Deus tenha criado o mundo alguns milhões de anos antes. Os que se perdem em semelhantes ficções não saberiam responder aos que argumentassem a favor da eternidade do mundo. Com efeito, não fazendo Deus nada sem razão e não podendo apontar nenhuma por que não criou o mundo antes, concluir-se-á que, ou ele não criou nada absolutamente, ou produziu o mundo antes de qualquer tempo assinalável, a saber, o mundo é eterno. Mas quando se mostra que o começo, qualquer que seja, é sempre a mesma coisa, cessa a questão por que não foi de outro modo. ${ }^{56}$

Por constituir apenas uma propriedade, ou seja, uma "certa ordem das coisas" 57 , o tempo não pode ser concebido antes da existência das coisas, pois é justamente em relação à sucessão destas que ele se compreende. Por isso, enquanto ordem contínua dos estados, o tempo não pode ser meio de discernimento das coisas.

Assim, alcançamos a intelecção de que o espaço e o tempo, para Leibniz, consistem em ordens relativas aos corpos, que não são suficientes para lhes oferecer distinção, uma vez que são eles (o espaço e o tempo) decorrentes das distinções destes, fundadas necessariamente em predicados internos, a saber, concernentes às substâncias individuais, que se atualizaram.

\section{Conclusão}

Esperamos ter esclarecido, ainda que minimamente, os pontos referentes à concepção leibniziana de espaço/tempo, principalmente no que diz respeito à sua relação com a indiscernibilidade dos objetos.

Partimos, em nossa primeira parte, da verificação das diferenças explícitas entre as concepções de Newton e Leibniz sobre o tema, mostrando como se constitui a relatividade proposta pelo último.

\footnotetext{
${ }^{55}$ Ibidem, p. 418.

${ }^{56}$ Ibidem, p 419-420.

${ }^{57}$ Ibidem, p. 420.
} 
Em nossa segunda parte, exploramos alguns usos da noção de "relatividade" na história da filosofia natural, partindo de Galileu e passando por Newton até chegarmos à física relativística de Einstein. Analisamos também como o problema da natureza do espaço é uma questão central na tradição filosófica desde a antiguidade. Vimos como o princípio da relatividade dos corpos em movimento na teoria da relatividade de Einstein é um caso do princípio de relatividade acerca da universalidade e invariância das leis da física. Pontuamos como o princípio da relatividade, tal como formulado por Einstein, assume o postulado relativístico de Leibniz: "não há movimento absoluto", ou, "nenhum movimento pode ser detectado tendo como referencial o espaço absoluto". Aqui devemos frisar que embora encontremos fontes a tal respeito, tais fontes não são numerosas, e no mais das vezes, o investigador da história da relatividade pode muito bem, ao final de um certo estudo, não ter conhecido a relação entre a relatividade do espaço em Leibniz e a física relativística de Einstein. Pontuar tal relação, ainda que já tenha sido feito em alguns trabalhos, continua de suma importância para aqueles que desejam lançar luz sobre os aspectos históricos e epistemológicos do problema da relatividade dos corpos em movimento na física.

Em seguida, investigamos as noções de ordem, intervalo, duração, lugar e relação, analisando por fim a distinção entre mundo real e ideal, a partir de onde o texto concentrou-se na problemática relação entre espaço e tempo e o princípio de identidade dos indiscerníveis. Mostramos que Leibniz sugere a necessidade de um existente fixo para que se conceba qualquer diferença de lugar ocupado por objetos, pois qualquer inversão, como o exemplo meridional por ele proposto e citado neste estudo, somente em relação a tal existente poderia ser imaginada enquanto tal.

Com isso, nos parece suficientemente demonstrado que, para Leibniz, a realidade se constitui a partir de uma razão suficiente, por meio de relações resultantes da necessidade de um melhor mundo dentre todos os possíveis. Desse modo, a relatividade do tempo e do espaço constitui o mundo material a partir da sua idealidade, como um todo contínuo, por onde se conclui que u ma "razão externa de discernir não poderia fundar-se senão na interna". ${ }^{58}$

A relatividade dos corpos em movimento na filosofia natural de Leibniz rompeu com uma longa tradição que, desde a antiguidade, concebia o espaço como entidade absoluta. Deste modo, Leibniz contribuiu para a criação de uma cosmovisão relativística. Não podemos ignorar que séculos depois, a teoria da relatividade de Einstein recolocaria a filosofia natural de Leibniz em primeiro plano, demonstrando sua fecundidade e atualidade.

${ }^{58}$ LEIBNIZ, ob. cit., p. 420. 


\section{Referências:}

AGASSI, J. Leibniz's place in the history of physics. Journal of the History of Ideas. Vol. 30, No. 3 (Jul. - Sep., 1969), p. 331-344.

BONDI, H. E. Relativity. Rept. Progr. Phys., 22, 97-120 (1959).

CARDENAS CASTANEDA, L; FLÓREZ, C. D. B. Leibniz, Mach y Einstein: Tres objeciones al espacio absoluto de Newton. discus.filos [online]. 2009, vol. 10, n. 15. <acesso em: 10/06/2019>.

CARUSO, F; OGURI, V. Física Moderna: Origens clássicas e fundamentos quânticos. Rio de Janeiro: Campus, 2006.

CASU, M; ALBERGANTE, L. Identity in the Real World. In. VALVERDÚ, J. Thinking Machines and the Philosophy of Computer Science. New York: IGI, 2010.

CHERNOFF, F. Leibniz's principle of identity of indiscernibles. In: Gottfried Wilhelm Leibniz: critical assessments. Routledge: Nova Yorque, 1994.

CINDRA, J.L. Esboço da evolução histórica do princípio de relatividade. Rev. Bras. Ensino Fís. [online]. Vol. 16 nr. 1 a 41994.

COCCHIARELLA, N.B. Formal Ontology and Conceptual Realism. Dordrecht: Springer, 2007.

COVER, J. A.; HARTZ, G. A. Space and Time in the Leibnizian Metaphysic. In: Gottfried Wilhelm Leibniz: critical assessments. Routledge: Nova Yorque, 1994.

EINSTEIN, A. Sobre o princípio da relatividade e suas implicações. Rev. Bras. Ensino Fís. [online]. 2005, vol. 27, n.1. <acesso em: 08/05/2019>

EINSTEIN, A. Meus últimos anos. Rio de Janeiro: Nova Fronteira, 2018.

EINSTEIN, A. Zur Elektrodynamic bewegter Körper. Annalen der Physik 17: 891-921. 1905.

ISHIGURO, H. Leibniz's philosophy of logic and language. Cambridge: Londres e Nova Yorque, 1990.

HUGGETT, N; HOEFER, C. Absolute and Relational Theories of Space and Motion. In: The Stanford Encyclopedia of Philosophy (Spring 2018 Edition), Edward N. Zalta (ed.),

URL $=<$ https://plato.stanford.edu/archives/spr2018/entries/spacetime-theories/>. <acesso em: 11/06/2019>.

KÖRNER, S. Kant. Tradução de Ignacio Zapata Tellechea, Madrid: Alianza, 1981.

LEIBNIZ, G. W. Coleção Os pensadores. Tradução: Carlos Lopes de Mattos, Abril Cultural: São Paulo, 1974.

. Discours de Métaphisique et Correspondance avec Arnauld. Paris: Vrin, 1993.

MARTINS, R. A. Física e História. Cienc. Cult. [online]. 2005, vol. 57, n.3 [cited 2019-06-12], p.25-29. <acesso em: 10/03/2019>

MENESES, R.D.B. Relatividade restrita de Einstein: Fundamentos filosóficos. Perspectiva Filosófica. Volume II, Número 24. Julho/Dezembro de 2005. 
NEWTON, I. W. Coleção Os pensadores. Tradução: Pablo Ruben Mariconda. Abril Cultural: São Paulo, 1974.

PLANCK, M. Autobiografia científica e outros ensaios. Tradução Estela dos Santos Abreu. Rio de Janeiro: Contraponto, 2012. p. 37.

POPPER, K. O mundo de Parmênides: Ensaios sobre o iluminismo pré-socrático. Roberto Leal Ferreira (Trad.). São Paulo: Editora Unesp, 2014.

ROCHA, A.N.; RIZZUTI, B.F; MOTA, D.S. Transformações de Galileu e de Lorentz: um estudo via teoria de grupos. Rev. Bras. Ensino Fís. [online]. 2013, vol. 35, n.4. <acesso em: 31/05/2019>

STACHEL, J. O manuscrito de Einstein de 1912 como pista para o desenvolvimento da teoria da relatividade restrita. Sci. stud. [online]. 2005, vol.3, n.4 [cited 2019-0612], p. 583-596. <acesso em: 10/06/2019>.

TUGENDHAT, Ernst, WOLF, Ursula. Propedêutica Lógico-semântica. Trad. de Fernando Augusto da Rocha Rodrigues. - Petrópolis, RJ : Vozes, 1997

WINTERBOURNE, A.T. On the Metaphysics of Leibnizian Space and time. In: Gottfried Wilhelm Leibniz: critical assessments. Nova York: Routledge, 1994.

Endereço dos Autores:

\section{André Luiz Bentes}

Rua Elisa de Albuquerque, 157 - Bl. 10 - Apto. 103

Todos os Santos

20770-290 Rio de Janeiro - RJ

andrebentes@gmail.com

\section{Vinicius Carvalho}

Rua Raimundo Prado, 1144

Centro

79490-000 São Gabriel do Oeste - MS

viniciusfilo@yahoo.com.br 